\title{
Pelatihan kesehatan terhadap pengetahuan tentang perawatan luka pasca operasi
}

\author{
Eka Yudha Chrisanto', Nur Afni², Andoko³ \\ 1Akademi Keperawatan Malahayati Bandar Lampung. Email: yudhachrisanto88@gmail.com \\ 2Rumah Sakit Umum Daerah Dr. A. Dadi Tjokrodipo, Kota Bandar Lampung. Email: nurafni@gmail.com \\ 3Program Studi Ilmu Keperawatan Universitas Malahayati Bandar Lampung. Email: andoko2013@gmail.com
}

\author{
Abstract \\ Impact of health educational program upon nurses' knowledge \\ Towards postoperative wounds care in Lampung-Indonesia
}

Background: The surgery in Indonesia ranks 11 th out of 50 treatments for disease patterns in hospitals in Indonesia, which is an estimated $32 \%$ of them were laparotomy. The number of abdominal surgical cases in Lampung Province in 2017 was (28.95\%) and increased in 2018 by (32.45\%).

Purpose: Know the effect of health training in knowledge and surgical wound management.

Methods: This type of study was quantitative, with the Pre-Experiment design and the design one group pre test - post test. The populations were all of postoperative patients and samples of 34 people with a total sampling technique. Data collection uses questionnaire sheets and the statistical test used dependent t-test.

Results: The average knowledge about postoperative wound care before being given health training of 14.18 and a standard deviation of 1.749 . The average knowledge about postoperative wound care after being given health training of 17.06 and a standard deviation of 3.142 , with $p$-value $=(0,000<0,05)$.

Conclusion: There was the effect of health training in knowledge and surgical wound management. Health workers are expected to be able to apply the provision of health training to postoperative patients to improve patient knowledge in subsequent care and be used as a reference for making policies regarding the provision of health training to postoperative patients.

\section{Keywords: Health educational program; Nurses; Knowledge; Postoperative wounds care}

Pendahuluan: Tindakan operasi di Indonesia menempati urutan ke-11 dari 50 pertama penanganan pola penyakit di rumah sakit se-Indonesia yang diperkirakan $32 \%$ diantaranya merupakan tindakan bedah laparatomi. Jumlah kasus bedah abdomen di Provinsi Lampung pada tahun 2017 sebesar $(28,95 \%)$ dan meningkat pada tahun 2018 sebesar (32,45\%).

Tujuan: Diketahui pengaruh pelatihan kesehatan terhadap pengetahuan tentang perawatan luka pasca operasi. Metode: Jenis penelitian kuantitatif, dengan rancangan penelitian Pra Experiment dan pendekatan one group pre test - post test design. Populasi seluruh pasien post operasi dan sampel sebanyak 34 orang dengan teknik total sampling. Pengumpulan data menggunakan lembar kuesioner dan menggunakan uji dependent t-test.

Hasil: Rata-rata pengetahuan tentang perawatan luka pasca operasi sebelum diberikan pelatihan kesehatan sebesar 14,18 dan standar deviasi sebesar 1,749. Rata-rata pengetahuan tentang perawatan luka pasca operasi sesudah diberikan pelatihan kesehatan sebesar 17,06 dan standar deviasi sebesar 3,142, dengan $p$-value $=$ $(0,000<0,05)$.

Simpulan: Ada pengaruh pelatihan kesehatan terhadap pengetahuan tentang perawatan luka pasca operasi. Diharapkan petugas kesehatan dapat mengaplikasikan pemberian pelatihan kesehatan kepada pasien pasca operasi untuk meningkatkan pengetahuan dalam perawatan selanjutnya dan dijadikan referensi untuk membuat kebijakan mengenai pemberian pelatihan kesehatan kepada pasien pasca operasi.

Kata Kunci: Pelatihan kesehatan; Pengetahuan; Perawatan luka 


\section{PENDAHULUAN}

Pembedahan melakukan tindakan pengobatan yang menggunakan cara invasif dengan membuka atau menampilkan bagian tubuh yang akan ditangani. Pembukaan tubuh ini umumnya dilakukan dengan membuat sayatan setelah bagian yang akan ditangani ditampilkan dan dilakukan tindakan perbaikan yang akan diakhiri dengan penutupan dengan penjahitan luka (Kozier, \& Erb, 2009; Sjamsuhidayat, 2012; Rustianawati, Karyati, \& Himawan, 2013). Secara garis besar pembedahan dibedakan menjadi dua yaitu bedah minor dan bedah mayor. Pada pembedahan mayor dilakukan pemberian anestesi yang terdiri dari dua jenis anestesi yaitu anestesi regional dan general anestesi. Bedah mayor merupakan tindakan pembedahan yang melibatkan organ tubuh secara luas dan mempunyai tingkat resiko yang tinggi terhadap kelangsungan hidup klien (Potter, \& Perry, 2006; Maryunani, 2014).

Jumlah pasien dengan tindakan operasi mencapai angka peningkatan yang sangat signifikan dari tahun ke tahun. Tercatat di tahun 2011 terdapat 140 juta pasien di seluruh rumah sakit di dunia, sedangkan pada tahun 2012 data mengalami peningkatan sebesar 148 juta jiwa (Rahmayati, Silaban, \& Fatonah, 2018).

Tindakan operasi di Indonesia menempati urutan ke-11 dari 50 pertama penanganan pola penyakit di rumah sakit se-Indonesia yang diperkirakan 32\% diantaranya merupakan tindakan bedah laparatomi (Kementerian Kesehatan Republik Indonesia, 2017). Jumlah kasus bedah abdomen di Provinsi Lampung pada tahun 2017 sebesar (28,95\%) dan meningkat pada tahun 2018 sebesar $(32,45 \%)$ (Dinas Kesehatan Provinsi Lampung, 2018).

Penghalang utama proses penyembuhan luka adalah jaringan nekrotik, pertumbuhan kuman atau infeksi, dan eksudat berlebih. Faktor-faktor yang dapat mendukung kesembuhan luka pasca operasi dan berpengaruh terhadap risiko infeksi luka operasi adalah pengaliran darah lokal, ada atau tidaknya edema, zat-zat pembakar dan pembangun, kebersihan luka, besarnya luka, kering atau tidaknya luka (Said, Taslim, \& Bahar, 2013; Maghfuri, 2015). Penyembuahan luka melalui proses pergantian dan perbaikan fungsi jaringan yang rusak. Fase-fase penyembuhan luka yaitu fase inflamasi berlangsung selama 1-4 hari, fase proliferatif berlangsung 5-20 hari, dan fase maturasi berlangsung 21 hari sampai sebulan bahkan tahunan (Purwoastuti, \& Walyani, 2015).

Ketidaksiapan pasien menghadapi pemulangan juga dapat terjadi karena pasien terlalu cepat dipulangkan sehingga hal ini juga berisiko terhadap terjadinya komplikasi pasca bedah setelah di rumah, dan juga dikarenakan pemulangan yang tidak direncanakan yang dapat berakibat kepada hospitalisasi ulang (Kusumayanti, 2014). Mayoritas pasien yang menerima informasi tentang nyeri dan manajemen luka, aktivitas, nutrisi, dan komplikasi pada umumnya merasakan bahwa tidak mengalami perasaan khawatir yang membuat mereka akan mengadakan kunjungan tidak rutin ke fasilitas kesehatan setelah dipulangkan. Sedangkan pasien yang tidak mendapat informasi tentang nyeri dan manajemen luka, mengalami kekhawatiran yang memaksa mereka untuk melakukan kunjungan tidak rutin kepada suatu fasilitas kesehatan setelah dipulangkan, oleh karena itu pasien perlu dipersiapkan untuk menghadapi pemulangan (Rohana, Kustriyani, \& Pribadi, 2015).

Pada tahun 2018, sebanyak 824 pasien bedah umum, diantaranya yang melakukan operasi bedah appendisitis sekitar $47,25 \%$, bedah laparotomy sebanyak $32,30 \%$ dan hernia sebanyak $12,45 \%$ sebanyak $7,12 \%$. Hasil pre survei pada Desember Tahun 2018 dengan melakukan observasi pada 10 pasien post operasi yang kontrol pada hari ke 1-5 diketahui pada luka post operasi terdapat $5(50 \%)$ mengalami penyembuhan luka yang abnormal, yakni keadaan luka yang tidak sesuai dengan fase, waktu, dan peristiwa penyembuhan luka. Saat dilakukan wawancara terdapat $80 \%$ diantaranya memiliki tingkat pengetahuan tentang perawatan luka pasca operasi kurang baik sehingga berpotensi terjadi infeksi pada luka. Jika hal ini dibiarkan maka dampak yang terjadi yaitu proses penyembuhan luka pada pasien pasca operasi akan berlangsung lama (RSUD Dr. A. Dadi. Tjokrodipo Kota Bandar Lampung, 2018).

\section{METODE PENELITIAN}

Jenis penelitian kuantitatif, dengan rancangan penelitian Pra Experiment dan pendekatan one group pre test - post test design. Penelitian ini sudah lulus kelaikan etik dari Komisi Etik Penelitian Kesehatan (KEPK) Universitas Malahayati dan dilaksanakan di RSUD Dr. A. Dadi. Tjokrodipo Kota Bandar Lampung pada Juni s/d Juli Tahun 2019. Populasi seluruh pasien post operasi dan sampel

Eka Yudha Chrisanto' Akademi Keperawatan Malahayati Bandar Lampung. Email: yudhachrisanto88@gmail.com Nur Afni ${ }^{2}$ Rumah Sakit Umum Daerah Dr. A. Dadi Tjokrodipo, Kota Bandar Lampung. Email: nurafni@gmail.com Andoko ${ }^{3}$ Program Studi llmu Keperawatan Universitas Malahayati Bandar Lampung. Email: andoko2013@gmail.com 
sebanyak 34 responden dengan teknik total sampling. Analisis data menggunakan uji dependent t-test untuk menguji perbedaan mean/rata-rata pengetahuan sebelum dan setelah diberikan pelatihan kesehatan.

Cara pengumpulan data dengan menggunakan lembar kuesioner. Lembar kuesioner untuk mengukur variabel pengetahuan menggunakan kuesioner terdiri dari 20 pertanyaan dengan rentang skor 0-20. Langkah pertama sebelum diberikan perlakuan pada pasien post operasi, terlebih dahulu peneliti mengukur pengetahuan (pretest) sebelum dilakukan pelatihan kesehatan dengan menggunakan alat ukur kuesioner. Selanjutnya melakukan pelatihan kesehatan pada pasien post operasi dengan lama waktu yaitu ratarata 30 menit, tahapan ini dilakukan di ruang perawatan bedah. Setelah dilakukan pelatihan kesehatan kemudian peneliti melakukan post test dengan menilai kembali pengetahuan menggunakan kuesioner.

\section{HASIL}

Tabel 1. Karakteristik Pendidikan Dan Pekerjaan Pasien N = 34

\begin{tabular}{lcc}
\hline Karakteristik & Frekuensi & Persentase \\
\hline Pendidikan: & 4 & 11,76 \\
SD & 10 & 29,42 \\
SMP & 12 & 35,29 \\
SMA & 8 & 23,53 \\
Perguruan Tinggi & & \\
Pekerjaan: & 8 & \\
PNS & 6 & 23,53 \\
Wiraswasta & 13 & 17,54 \\
Buruh & 7 & 38,24 \\
Tidak Bekerja & & 20,59 \\
\hline
\end{tabular}

Berdasarkan Tabel 1. maka dapat diketahui bahwa karakteristik pendidikan pasien pasca operasi, sebagian besar adalah SMA sebanyak 12 responden (35,29\%). Pekerjaan sebagian besar adalah buruh sebanyak 13 responden $38,24 \%$ ).

Tabel 2. Rata-Rata Pengetahuan Sebelum Dan Sesudah Pelatihan Kesehatan N = 34

\begin{tabular}{ccccc}
\hline Kelompok & Mean & SD & SE & Min-max \\
\hline Sebelum & 14,18 & 1,749 & 0,300 & $11-18$ \\
Sesudah & 17,06 & 3,142 & 0,539 & $12-23$ \\
\hline
\end{tabular}

Hasil penelitian dari Tabel 2. memperlihatkan bahwa rata-rata pengetahuan tentang perawatan luka pasca operasi sebelum diberi pelatihan kesehatan mempunyai nilai rata-rata 14,18 dan standar deviasi sebesar 1,749. Nilai minimal 11 dan maksimal 18. Sedangkan, hasil penelitian memperlihatkan bahwa rata-rata pengetahuan tentang perawatan luka pasca operasi sesudah diberi pelatihan kesehatan media isi piringku mempunyai nilai rata-rata 17,06 dan standar deviasi sebesar 3,142 dan. Nilai minimal 12 dan maksimal 23.

Eka Yudha Chrisanto' Akademi Keperawatan Malahayati Bandar Lampung. Email: yudhachrisanto88@gmail.com Nur Afni ${ }^{2}$ Rumah Sakit Umum Daerah Dr. A. Dadi Tjokrodipo, Kota Bandar Lampung. Email: nurafni@gmail.com Andoko $^{3}$ Program Studi llmu Keperawatan Universitas Malahayati Bandar Lampung. Email: andoko2013@gmail.com 
Pelatihan kesehatan terhadap pengetahuan tentang perawatan luka pasca operasi

Tabel 3. Pengaruh Pelatihan Kesehatan Terhadap Pengetahuan N = 34

\begin{tabular}{cccccc}
\hline Kelompok & Mean & SD & t & p-value & $\begin{array}{c}\text { Perbedaan rerata } \\
\text { Cl 95\% }\end{array}$ \\
\hline Sebelum & 14,18 & 1,966 & 8,549 & 0,000 & 2,882 \\
Sesudah & 17,06 & & & & $3,568-2,196$ \\
\hline
\end{tabular}

Hasil analisis dari tabel 3 diatas dapat diketahui perbedaan rata-rata pengetahuan tentang perawatan luka pada pasien pasca operasi sebelum dan sesudah diberikan pelatihan kesehatan sebesar 2,882 dan standar deviasi sebesar 1,966. Hasil uji diperoleh nilai $p=(0,000<0,05)$ sehingga ada pengaruh pelatihan kesehatan terhadap pengetahuan tentang perawatan luka pasca operasi, diperoleh nilai OR sebesar 15,400.

\section{PEMBAHASAN}

\section{Pengetahuan Sebelum Dan Sesudah Diberi Pelatihan Kesehatan}

Berdasarkan hasil dari pengolahan data maka dapat diketahui bahwa rata-rata pengetahuan tentang perawatan luka pasca operasi sebelum diberi pelatihan kesehatan mempunyai nilai ratarata 14,18 dan standar deviasi sebesar 1,749. Nilai minimal 11 dan maksimal 18. Rata-rata pengetahuan sesudah diberi pelatihan kesehatan media isi piringku mempunyai nilai rata-rata 18,06 dan standar deviasi sebesar 2,400 dan. Nilai minimal 12 dan maksimal 23.

Perilaku manusia pada hakikatnya suatu aktivitas dari manusia itu sendiri. Oleh sebab itu, perilaku manusia itu mempunyai bentangan yang sangat luas mencakup berjalan, berbicara, bereaksi, berpakaian dan lain sebagainya. Bahkan kegiatan internal (internal activity) seperti berfikir, persepsi dan emosi yang merupakan perilaku manusia. Pengetahuan terjadi setelah seseorang melakukan penginderaan terhadap suatu objek tertentu. Tanpa pengetahuan seseorang tidak mempunyai dasar untuk mengambil keputusan dan menentukan tindakan terhadap masalah yang dihadapi (Notoatmodjo, 2014).

Pengetahuan yang dimiliki seseorang dapat dipengaruhi oleh faktor informasi yang diperoleh baik dari pendidikan formal maupun non formal dapat memberikan pengaruh jangka pendek (immediate impact) sehingga menghasilkan perubahan atau peningkatan pengetahuan (Riyanto, 2013).

Pelatihan kesehatan dimana terjadinya proses perubahan perilaku yang dinamis, perubahan tersebut bukan sekadar proses transfer materi/teori dari seorang ke orang lain dan bukan pula seperangkat prosedur, akan tetapi perubahan tersebut terjadi karena adanya kesadaran dari dalam individu, kelompok atau masyarakat sendiri. Tujuan utama pelatihan kesehatan agar orang mampu menetapkan masalah dan kebutuhan mereka sendiri, memahami apa yang dapat mereka lakukan terhadap masalahnya, dengan sumber daya yang adapada mereka ditambah dengan dukungan dari luar dan memutuskan kegiatan yang tepat guna untuk meningkatkan taraf hidup sehat dan kesejahteraan masyarakat (Mubarak, \& Chayatin, 2014).

Sejalan dengan penelitian terdahulu, diperoleh tingkat pengetahuan sebelum pemberian pelatihan kesehatan yaitu mean 16.33 , median 17,00 , tingkat pengetahuan sesudah pemberian pelatihan kesehatan yaitu mean 15,90 median 16,00 (Rohana, Kustriyani, \& Pribadi, 2015).

Hasil penelitian dapat diketahui sebagian besar tingkat pengetahuan pasien sesudah diberikan pelatihan kesehatan lebih tinggi dibandingkan tingkat pengetahuan responden sebelum diberikan pelatihan kesehatan. Hal ini terjadi karena pelatihan kesehatan yang diberikan pada pasien pasca operasi yang meliputi pengetahuan tentang perawatan luka operasi, mengatasi rasa nyeri luka operasi, hal-hal yang perlu dihindari oleh pasien pasca operasi, aktivitas pasien pasca operasi, nutrisi pasien pasca operasi, pemakaian obat oleh pasien pasca operasi. Berdasarkan hal tersebut peneliti berpendapat bahwa pengetahuan responden tentang tentang perawatan luka pasca operasi tersebut dikarenakan kurangnya penginderaan mereka terhadap informasi mengenai perawatan luka pasca operasi yang berdampak pada pengetahuan responden tersebut dalam perilaku kesehatan. Untuk itu disarankan responden agar dapat memanfaatkan pengetahuan tentang perawatan luka pasca operasi untuk mempercepat penyembuhan.

Eka Yudha Chrisanto' Akademi Keperawatan Malahayati Bandar Lampung. Email: yudhachrisanto88@gmail.com Nur Afni ${ }^{2}$ Rumah Sakit Umum Daerah Dr. A. Dadi Tjokrodipo, Kota Bandar Lampung. Email: nurafni@gmail.com Andoko ${ }^{3}$ Program Studi llmu Keperawatan Universitas Malahayati Bandar Lampung. Email: andoko2013@gmail.com 
Pelatihan kesehatan terhadap pengetahuan tentang perawatan luka pasca operasi

\section{Pengaruh Pelatihan Kesehatan Terhadap Pengetahuan Tentang Perawatan Luka Pasca Operasi}

Perbedaan rata-rata pengetahuan tentang perawatan luka pada pasien pasca operasi sebelum dan sesudah diberikan pelatihan kesehatan sebesar 2,882 , dan standar deviasi sebesar 1,966 . Hasil uji diperoleh nilai $p=(0,000<0,05)$ sehingga ada pengaruh pelatihan kesehatan terhadap pengetahuan tentang perawatan luka pasca operasi.

Pelatihan kesehatan diaplikasi atau diterapkan didalam bidang kesehatan. Secara operasional pelatihan kesehatan untuk memberikan dan atau meningkatkan pengetahuan, sikap, dan praktek baik individu, kelompok atau masyarakat dalam memelihara dan meningkatkan kesehatan mereka sendiri. Metode pelatihan kesehatan dengan penerapan pelatihan di dalam bidang kesehatan, secara operasional semua kegiatan untuk memberikan atau meningkatkan pengetahuan (Notoatmojo, 2014).

Pengetahuan terjadi setelah orang melakukan penginderaan terhadap suatu objek tertentu. Penginderaan itu terjadi melalui panca indera manusia yakni indera penglihatan, pendengaran, penciuman, rasa dan raba. Sebagian besar penginderaan manusia diperoleh melalui mata dan telinga. Pengetahuan kognitif merupakan domain yang sangat penting dalam membentuk tindakan seseorang (overt behavior) (Notoatmodjo, 2014).

Intervensi keperawatan dibutuhkan karena adanya ketidakmampuan untuk melakukan perawatan diri sebagai akibat dari adanya keterbatasan. Salah satu bentuk intervensi keperawatan yang dapat dilakukan dengan pelatihan kesehatan. Pelatihan kesehatan pada hakikatnya kegiatan atau usaha untuk menyampaikan pesan kesehatan kepada masyarakat, kelompok atau individu. Harapan dengan adanya pesan tersebut masyarakat, keluarga atau individu dapat memperoleh pengetahuan tentang kesehatan yang lebih baik (Notoatmodjo, 2012).

Hal ini juga sejalan dengan pendapat peneliti lain bahwa pasien yang menerima informasi tentang nyeri dan manajemen luka, aktivitas, nutrisi, dan komplikasi pada umumnya merasakan bahwa tidak mengalami perasaan khawatir yang membuat mereka akan mengadakan kunjungan tidak rutin ke fasilitas kesehatan setelah dipulangkan. Sedangkan pasien yang tidak mendapat informasi tentang nyeri dan manajemen luka, mengalami kekhawatiran yang memaksa mereka untuk melakukan kunjungan tidak rutin kepada suatu fasilitas kesehatan setelah dipulangkan, oleh karena itu pasien perlu dipersiapkan untuk menghadapi pemulangan (Rohana, Kustriyani, \& Pribadi, 2015).

Penelitian ini sejalan dengan penelitian sebelumnya dengan menggunakan uji statistik Wilcoxon didapatkan p-value $=0,000<$ (a) $0,05 \%$. Ada pengaruh pendidikan kesehatan perawatan luka terhadap tingkat pengetahuan dan sikap pertolongan pertama pada siswa (Lasut, Mulyadi, \& Killing, 2018).

Penelitian lainnya dengan menggunakan kuesioner dan dianalisis menggunakan uji Wilcoxon. Hasil uji statistik menunjukkan ada pengaruh pelatihan kesehatan terhadap tingkat pengetahuan pasien tentang perawatan pasca operasi dengan $p=0,009$ dan $a=0,05$ (Rohana, Kustriyani, \& Pribadi, 2015).

Menurut peneliti, pelatihan kesehatan upaya untuk meningkatkan pengetahuan dan kesadaran, disamping sikap dan perilaku. Peningkatan pengetahuan sesudah diberikan pelatihan kesehatan terjadi karena adanya perlakuan yang diberikan pada responden berupa pelatihan kesehatan media isi piringku gerakan masyarakat hidup sehat. Setelah mendapatkan stimulus berupa pelatihan kesehatan, dalam diri seseorang terjadi proses penerimaan pengetahuan dimana orang tersebut menyadari dalam arti mengetahui terlebih dahulu terhadap stimulus (objek). Dalam hal ini responden menyadari dan mengetahui adanya pelatihan kesehatan tentang perawatan luka pasca operasi yang berisi materi mengenai pengertian, cara perawatan luka, faktor yang mempengaruhi penyembuhan luka dan fase penyembuhan luka. Setelah itu interest (merasa tertarik), yaitu orang tersebut mulai tertarik terhadap stimulus atau objek tersebut. Di sini sikap subjek sudah mulai timbul. Responden merasa tertarik untuk mengikuti penyuluhan dan antusias dalam mendengarkan materi yang disampaikan dalam pelatihan kesehatan.

\section{SIMPULAN}

Sebagian besar pasien berpendidikan SMA sebanyak 12 responden (35,29\%). Pekerjaan sebagian besar yaitu buruh sebanyak 13 responden $38,24 \%$ ). Rata-rata pengetahuan tentang perawatan luka pasca operasi sebelum diberikan pelatihan kesehatan yaitu 14,18 dan standar deviasi sebesar 1,749 , sementara rata-rata sesudah diberikan pelatihan kesehatan yaitu 17,06 dan standar deviasi sebesar 3,142. Ada pengaruh pelatihan kesehatan terhadap pengetahuan tentang perawatan luka pasca operasi dengan $p=(0,000<0,05)$

Eka Yudha Chrisanto' Akademi Keperawatan Malahayati Bandar Lampung. Email: yudhachrisanto88@gmail.com Nur Afni ${ }^{2}$ Rumah Sakit Umum Daerah Dr. A. Dadi Tjokrodipo, Kota Bandar Lampung. Email: nurafni@gmail.com Andoko $^{3}$ Program Studi llmu Keperawatan Universitas Malahayati Bandar Lampung. Email: andoko2013@gmail.com 


\section{SARAN}

Diharapkan bagi petugas kesehatan dapat mengaplikasikan pemberian pelatihan kesehatan kepada pasien pasca operasi untuk meningkatkan pengetahuan pasien dalam perawatan selanjutnya dan dijadikan referensi untuk membuat kebijakan mengenai pemberian pelatihan kesehatan kepada pasien pasca operasi.

Disarankan bagi responden agar dapat memanfaatkan pengetahuan tentang perawatan luka pasca operasi yang telah diberikan perawat, untuk dapat dilaksanakan saat pasien dirumah agar mempercepat penyembuhan luka operasi, serta menjaga kebersihan luka agar tidak mengalami infeksi.

\section{DAFTAR PUSTAKA}

Dinas Kesehatan Provinsi Lampung. (2018). Profil Dinas Kesehatan Provinsi Lampung. Lampung: Dinkes Provinsi Lampung.

Kementerian Kesehatan Republik Indonesia. (2017). Data dan informasi profil kesehatan Indonesia 2016. Jakarta: Pusat Data dan Informasi Kementerian Kesehatan RI.

Kozier, B., \& Erb, G. (2009). Buku ajar praktik keperawatan klinis. Jakarta: EGC.

Kusumayanti, P. D. (2014). Faktor-faktor yang berpengaruh terhadap lamanya perawatan pada pasien pasca operasi laparatomi. Coping (Community of Publishing in Nursing), 3(1).

Lasut, N. G. C., Mulyadi, N., \& Killing, M. (2018). Pengaruh pendidikan kesehatan perawatan luka akibat kecelakaan terhadap tingkat pengetahuan dan sikap pertolongan pertama pada siswa kelas $x$ di SMK Negeri 6 Manado. Jurnal Keperawatan,6(1).

Maghfuri, A. (2015). Keterampilan Dasar Perawatan Luka Bagi Pemula. Jakarta: TIM.

Maryunani. A. (2014). Asuhan Keperawatan Peri Operatif-Pre Operasi (Menjelang Pembedahan). Jakarta: Trans Info Media.

Mubarak, W. I., \& Chayatin, N. (2014). IImu kesehatan masyarakat: teori dan aplikasi. Jakarta: Salemba Medika.
Notoatmodjo, S. (2012). Pendidikan dan perilaku kesehatan. Jakarta: Rineka Cipta.

Notoatmodjo, S. (2014). Ilmu Perilaku. Jakarta: Penerbit PT. Rineka Cipta.

Notoatmodjo, S. (2014). Promosi Kesehatan. Jakarta: Penerbit PT. Rineka Cipta.

Potter, P. A., \& Perry, A. (2006). Buku Ajar Fundamental Keperawatan, Volume 2, Edisi 4. Penerbit Buku Kedokteran EGC, Jakarta.

Purwoastuti, E., \& Walyani, E. S. (2015). IImu Obstetri dan Ginekologi Sosial Bagi Kebidanan. Yogyakarta: PT. Pustaka Baru.

Rahmayati, E., Silaban, R. N., \& Fatonah, S. (2018). Pengaruh Dukungan Spritual terhadap Tingkat Kecemasan pada Pasien Pre-Operasi. Jurnal Kesehatan, 9(1), 138-142.

Riyanto, A. (2013). Kapita selekta kuesioner pengetahuan dan sikap dalam penelitian kesehatan. Jakarta: Salemba Medika.

Rohana, N., Kustriyani, M., \& Pribadi, L. S. (2012). Pengaruh pendidikan kesehatan terhadap tingkat pengetahuan pasien tentang perawatan pasca operasi di Ruang Amarilis I RSUD Tugurejo Semarang.

Rumah Sakit Umum Daerah Dr. A. Dadi Tjokrodipo. (2018). Data rekam medik. Bandar Lampung: RSUD Dr. A. Dadi. Tjokrodipo Kota Bandar Lampung.

Rustianawati, Y., Karyati, S., \& Himawan, R. (2013). Efektivitas ambulasi dini terhadap penurunan intensitas nyeri pada pasien post operasi laparatomi di RSUD Kudus. Jurnal IImu Keperawatan dan Kebidanan, 4(2).

Said, S., Taslim, N. A., \& Bahar, B. (2013). Gizi dan Penyembuhan Luka. Jakarta: EGC.

Sjamsuhidayat. (2012). Buku Ajar IImu Bedah. Edisi 3. Jakarta : EGC.

Eka Yudha Chrisanto' Akademi Keperawatan Malahayati Bandar Lampung. Email: yudhachrisanto88@gmail.com Nur Afni ${ }^{2}$ Rumah Sakit Umum Daerah Dr. A. Dadi Tjokrodipo, Kota Bandar Lampung. Email: nurafni@gmail.com Andoko $^{3}$ Program Studi llmu Keperawatan Universitas Malahayati Bandar Lampung. Email: andoko2013@gmail.com 